\title{
Biomarker bei infektiösen und nicht infektiösen Lungenerkrankungen außer Malignome
}

\author{
Biomarker in Pulmonary Diseases
}

Autoren

Institute

\author{
A. Gillissen ${ }^{1}$, V. Wiechmann ${ }^{2}$, U. R. Jürgens ${ }^{3}$
}

Robert-Koch-Klinik, Thoraxzentrum des Klinikums St. Georg, Leipzig

2 Institut für Pathologie und Tumordiagnostik des Klinikums St. Georg, Leipzig

3 Schwerpunkt Pneumologie, Allergologie, Schlafmedizin, Medizinische Klinik und Poliklinik II, Universitätsklinik Bonn eingereicht 29.1.2009

akzeptiert nach Revision 15. 5.2009

\section{Bibliografie}

DOI 10.1055/s-0029-1214799

Pneumologie 2009; 63:

439-450 @ Georg Thieme Verlag KG Stuttgart · New York ISSN 0934-8387

\section{Korrespondenzadresse \\ Prof. Dr. A. Gillissen \\ Robert-Koch-Klinik, \\ Thoraxzentrum des Klinikums \\ St. Georg \\ Nikolai-Rumjanzew-Str. 100 \\ 04207 Leipzig \\ www.rkk-leipzig.de}

\section{Zusammenfassung \\ $\nabla$}

Biomarker haben einen festen Stellenwert in der Medizin und unterstützen in der Diagnosestellung, sie weisen eine für bestimmte Erkrankungen prädiktive Wertigkeit auf, helfen $u$.U. besser die eingeleitete Therapie zu steuern und den klinischen Verlauf der betroffenen Patienten zu überwachen. Allerdings ist nur ein kleiner Teil der Vielzahl an untersuchten Markern für die Betreuung pneumologischer Patienten von verlässlichem Wert, wie z.B. Procalcitonin in der Therapiesteuerung von Patienten mit einer Pneumonie oder einer Sepsis, der Alpha-1-Antitrypsin-Serumspiegel bei Alpha-1-Antitrypsin-Mangelpatienten, die D-Dimere in der Diagnostik einer Lungenembolie oder einer Venenthrombose, Stickstoffmonoxid beim Asthma oder die Keimisolation im Sputum zur antibiogrammgerechten Antibiotikatherapie bei der chronisch-obstruktiven Lungenerkrankung oder der Pneumonie. Der qualitative Nachweis und die Quantifizierung von Markern im Atemkondensat oder der Nachweis von Molekülen in der Ausatemluft sind neue, noch nicht etablierte Verfahren, die möglicherweise in der Zukunft helfen werden, bestimmte Erkrankungen besser zu diagnostizieren oder zu therapieren. Grundsätzlich haben Biomarker, zusammen mit den übrigen uns zur Verfügung stehenden Verfahren, nur einen unterstützenden, nichtsdestotrotz aber einen wichtigen praktischen Wert. In dieser Übersicht wird anhand von neueren Studienergebnissen die Wertigkeit von Biomarkern bei nicht malignen Erkrankungen der Atemwege und der Lungen beleuchtet.

\section{Einleitung \\ $\nabla$}

Es gibt keine einheitliche Biomarker-Definition. Je nach Fachgebiet wird der Begriff Biomarker z.T. in sehr unterschiedlicher Weise angewendet. In der Medizin können Biomarker als messbare Produk-

\section{Abstract \\ $\nabla$}

Biological markers in various compartments of the human body have demonstrated potential value in diagnosis, prediction, guidance of therapy as well as in monitoring the clinical course of diseases of the airways and the lung. But only certain surrogate parameters are from clinical value, such as procalcitonin in pneumonia and sepsis, alpha-1-antitrypsin to diagnose alpha-1-antitrypsin deficiency, D-Dimere to detect emboli, nitric oxide in exhaled air in asthma, or isolation of germs from sputum to guide antibiotic treatment. Quantification of numerous markers in exhaled breath condensate or the detection of compounds in exhaled air are more recent attempts to further elucidate those biomarkers for clinical use. In general, biomarkers have an important supportive value in addition to routine diagnostic methods. The article reviews recent data regarding the usefulness of markers in non-malignant pulmonary diseases.

te, die als Indikatoren z. B. für Umweltbelastungen oder Krankheiten herangezogen werden können, definiert werden. Man kann zwischen integralen und spezifischen Biomarkern unterscheiden, wobei integrale Biomarker eine Menge von möglichen Abweichungen anzeigen, während spezifi- 
sche Biomarker einzelne Indikatoren für eine konkrete Situation, z. B. einen Stoffwechselschritt, beschreiben. Bezogen auf die Medizin sind Biomarker somit Faktoren, die sich aus Körperflüssigkeiten oder Zellen isolieren und meist auch quantifizieren lassen und einen (medizinischen) Zustand anzeigen. Sie haben somit im Idealfall eine diagnostische Aussagekraft, eignen sich zur Prognoseabschätzung, zu Therapieentscheid und -steuerung sowie zur Einschätzung der Schwere der zugrunde liegenden Erkrankung. Sie können z.B. auf das Fortschreiten einer Erkrankung hinweisen oder den Behandlungserfolg oder -misserfolg definieren. Entscheidend ist für den praktischen Einsatz in der Medizin, ob ein oder mehrere Biomarker für die erwartete Zielaussage eine hohe Spezifität und Sensitivität besitzen, die diagnostische mit anderen Methoden erzielbare Aussage erhärten oder bestätigen können. Ist das nicht der Fall oder wird der/die Biomarker von Störfaktoren beeinflusst, ist die Bestimmung des/der Biomarker nur bedingt verwertbar oder sinnlos.

Es gibt im pneumologischen Fachgebiet keine Erkrankung, zu der nicht irgendein Biomarker evaluiert wurde. Ziel dieser Übersicht ist es, an pneumologisch wichtigen Erkrankungen die Wertigkeit neuerer Biomarker oder älterer Biomarker, zu denen es neuere, für die praktische Anwendung wichtige Studienergebnisse gibt, exemplarisch vorzustellen.

Die Fülle der möglichen Biomarker ist unübersehbar und variiert ständig, weil täglich neue hinzukommen oder alte verworfen werden. Ungeachtet dessen haben sich viele Biomarker in der pneumologischen Diagnostik durchgesetzt und besitzen eine überaus wichtige Aussagekraft mit entsprechender Konsequenz für die Therapiesteuerung, wie z.B. aus dem Blut bestimmte Laborwerte. Wegen dieser Informationsfülle und aus Gründen der besseren Übersicht konnten in dieser Übersicht nur Teilaspekte dieses Themas beleuchtet werden. Der Fokus liegt auf Biomarkern nicht maligner Erkrankungen. Zudem wurden Aspekte zur Genetik und die broncho-alveoläre Lavage (BAL) ausgeklammert. Wo eine Abschätzung der Wertigkeit bestimmter Biomarker möglich und eine solche anerkannt ist, wurde diese vorgenommen.

\section{COPD}

Ziel der ECLIPSE-(Evaluation of COPD Longitudinally to identify Predictive surrogate End-points)-Studie ist es unter anderem, mit Hilfe von aus dem Blut, Urin, Sputum und Atemkondensat zu bestimmenden Biomarkern COPD-Subgruppen zu identifizieren [1]. Alleine die Durchführung eines solchen Studienansatzes weist darauf hin, dass es keine Biomarker gibt, mit denen sicher z. B. zwischen einem Asthma und einer COPD oder zwischen Therapie-Responder oder -non-Responder unterschieden werden kann oder die eine für den praktischen Patientenumgang bedeutungsvolle prognostische Aussage erlauben würden.

\section{Sputum}

Der in den Atemwegen der COPD und damit auch im Sputum dominierende Zelltyp sind die neutrophilen Granulozyten [2]. Der steigende Anteil von Sputumneutrophilen ist mit steigenden Sputumkonzentrationen von IL- (Interleukin) 8 und MPO (Myeloperoxidase) und mit einem schnelleren $\mathrm{FEV}_{1}$-Abfall pro Jahr assoziiert [3]. Eine erhöhte Sputum-Eosinophilenanzahl ( $\geq 1,3 \%)$ ist dagegen mit einem besseren Therapieansprechen (FEV1, Dyspnoesymptomatik, Gehstrecke) auf Kortikosteroide assoziiert, als bei Patienten, bei denen im Sputum eine neutrophile Entzün- dung dominierte $[4,5]$. Im Sputum sind in der Vergangenheit darüber hinaus eine Fülle von Entzündungsmediatoren quantifiziert worden, die mit der COPD und der Lungenfunktionseinschränkung korrelieren sollen, z. B. IL-8, LTC-4, MCP-1, Lipocalin, Metallo- und andere -Proteasen, diverse Leukotriene und Proteasen $[6-8]$.

Während einer Exazerbation steigen die im Sputum gemessenen Entzündungsmediatoren und der Anteil an neutrophilen Granulozyten an. Das Vorhandensein einer bakteriellen bronchialen Infektion korreliert mit dem Anteil neutrophiler Granulozyten im Sputum. Eine gelbliche oder gelb-grünliche Verfärbung des Sputums weist ebenfalls auf einen bakteriellen Infekt hin und gilt als Marker zur Indikation einer Antibiotikatherapie [9]. Darüber hinaus erwies sie sich als positiver prognostischer Marker eines Antibiotikatherapieerfolgs [9]. Obwohl der Eosinophilenanteil im Sputum eher ein Charakteristikum des Asthmas ist, wurde auch bei der COPD ein solcher Anstieg sowohl in der stabilen Erkrankungsphase als auch während der Exazerbation mit erhöhten ECP-(eosinophiles cationisches Protein)-Werten beobachtet. Darüber hinaus wurden bei der Exazerbation sowohl in der Bronchialschleimhautbiopsie als auch im Sputum erhöhte CD-8-positive T-Lymphozyten und reduzierte CD-4-positive T-Zellen nachgewiesen [10-12].

Das Sputum eignet sich bei ordnungsgemäßer Abnahme zur bakteriologischen Diagnostik einschließlich Keimisolation, Bestimmung der Keimzahl und Durchführung eines Antibiogramms $[13,14]$. Zusammenfassend hat nur die Beurteilung der Sputumfarbe und die aus dem Sputum durchführbare bakteriologische Diagnostik Eingang in die tägliche Routine gefunden, nicht jedoch die Fülle aller anderen Sputum-Biomarker [15-17].

\section{Bronchialschleimhautbiopsie}

In der Bronchialschleimhautbiopsie ( $\bullet$ Abb. 1 u. 2) wurden bei einer Exazerbation mehr eosinophile Granulozyten, Lymphozyten, Eotaxien, CCR-3 nachgewiesen $[11,18,19]$.

Zudem steigt auch der Anteil von Neutrophilen und deren Stoffwechselprodukte während einer Exazerbation an, ohne dass sich die chemotaktischen Eigenschaften vom Sputum erhöhen [20]. Schleimhautbiopsien der Atemwege haben für die COPD-Diagnostik- und Therapiesteuerung keine Wertigkeit in der täglichen Praxis sind aber evtl. für klinische Medikamentenprüfungen zur Evaluation etwaiger Medikamentenwirkungen auf zellulärer Ebene bzw. pathophysiologischer Zusammenhänge aus wissenschaftlicher Sicht interessant.

\section{Atemkondensat}

Im Atemkondensat wurden bei COPD-Patienten u.a. pH, H2O2, Zytokine, Leukotriene, Isoprostane, Nitrit/Nitrat und für den oxidativen Stoffwechsel bedeutsame Entzündungsmarker quantifiziert [21]. Viele dieser Marker korrelierten mit klinischen Parametern. So wurden z. B. H2O2, Interleukine, Leukotriene, Prostaglandin E2 (PGE2) und 8-Isoprostane bei der Exazerbation erhöht gemessen oder sie sinken bei einer erfolgreichen Therapie im weiteren Verlauf nach Exazerbation. Eine gute Lungenfunktion (FEV1) prädisponiert dagegen für niedrige Entzündungsmarker im Atemkondensat und umgekehrt [22 - 24]. Die Daten sind aber nicht einheitlich, was vor allem an dem methodischen Problem der im Atemkondensat niedrigen, meist knapp über der unteren Nachweisgrenze gemessenen Substanzkonzentrationen liegt [21]. Zudem ist die Reproduzierbarkeit von der Sammel- und Analysetechnik der Exhalatflüssigkeit abhängig, und die Metho- 


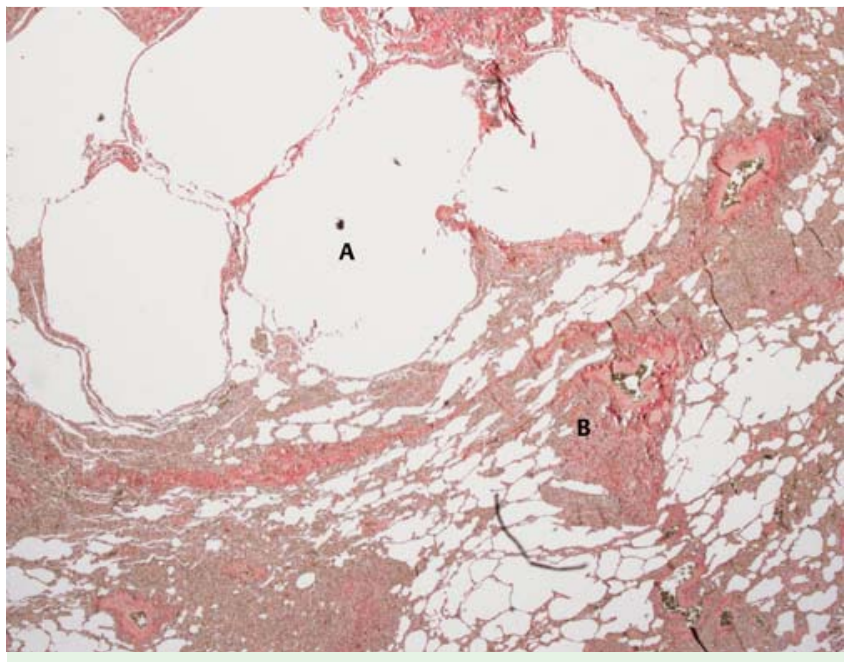

Abb. 1 Lungenbiopsie bei einem COPD-Patienten mit einem ausgeprägten Lungenemphysem und Mischstaubsilikose; v. Gieson Färbung, $\times 5$. A: Emphysemblasen, B: Staubeinlagerungen.

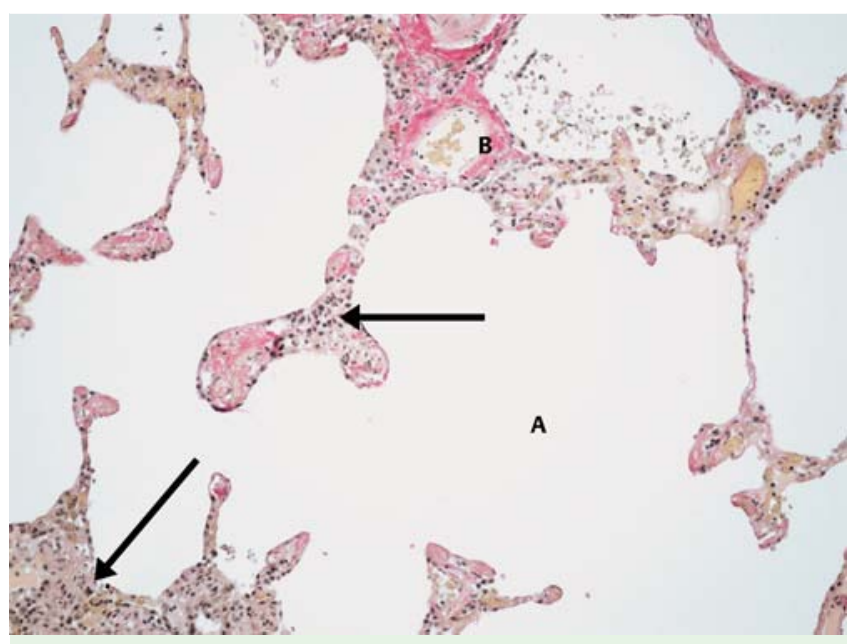

Abb. 2 Lungenbiopsie bei einem COPD-Patienten mit einem Lungenemphysem. Deutlich sind die Ansammlungen von mononukleären und granulozytären Zellen (Pfeile) erkennbar; v. Gieson, × 20. A: Emphysemblasen, B: Pulmonalarteriole.

de ist bis heute nicht verlässlich validierbar, was eine Vergleichbarkeit zwischen den publizierten Studien erschwert [25-27].

\section{Exhaliertes Stickstoffmonoxid (FeNO)}

Die Höhe des exhalierten Stickstoffmonoxids (FeNO) korreliert mit dem Anteil eosinophiler Granulozyten in den Atemwegen, weswegen sie sich in der Asthmadiagnostik (s.u.) eignet [2831]. Da in den Atemwegen von COPD-Patienten typischerweise ein erhöhter Neutrophilenanteil dominiert und zudem Zigarettenrauchen FeNO senkt, besitzen FeNO-Messungen bei der stabilen COPD keinerlei zusätzlichen Aussagewert [29,31].

\section{Labordiagnostik aus dem Blut}

Wie auch schon im Sputum und in der BAL sind bei COPD-Patienten im Vergleich zu den gesunden Kontrollen die Neutrophilenzahlen im peripheren Blut zusammen mit dem zellulären Aktivitätsstatus dieser Zellen erhöht. Auch der Anteil an zirkulierenden CD-8-positiven T-Lymphozyten ist höher als bei den nicht rauchenden Kontrollen [32]. Pulmonale Kachexie und Muskelatrophie korrelieren mit einem Anstieg der systemischen Inflamma- tion, gemessen an erhöhten TNF $\alpha$, IL-6 und Interferon-GammaSpiegeln [33,34]. Im Vergleich zu gesunden Kontrollen waren des Weiteren folgende Mediatoren im Blut von COPD-Patienten erhöht gemessen worden: IL-8, MMP-9, MCP-1, VEGF (vaskulärer endothelialer Wachstumsfaktor), ECP, MPO, ICAM, CD40L und Endothilin-1 [35]. Zusätzlich steigen während der Exazerbation die Plasmaspiegel für Fibrinogen (Fbg) und IL-6 und einige andere an, einschließlich ECP, löslicher IL-5-Rezeptor alpha, Interferon-induziertes Protein C oder Plasmaamyloid A [36].

Das C-reaktive Protein (CRP) wurde bei COPD-Patienten im Blut erhöht gemessen und als mortalitätshinweisender und damit prognostisch bedeutsamer Faktor diskutiert [7]. Insgesamt zeigen die CRP-Studien allerdings ein uneinheitliches Ergebnis, da nicht alle Patienten mit einer Exazerbation auch erhöhte CRPSpiegel aufwiesen. Zudem sind erhöhte CRP-Konzentrationen unspezifisch und lassen weder eine verlässlich Aussage über die zugrunde liegende Infektion (Bakterien oder Viren) noch eine prognostische Aussage über den weiteren Erkrankungsverlauf in Bezug auf COPD-Exazerbationsrate, die Lungenfunktion oder die Hospitalisierungsrate zu [37].

Im Gegensatz zur ambulant erworbenen Pneumonie wird die Bedeutung einer Procalcitonin-basierten Therapiesteuerung bei der COPD-Exazerbation bzgl. der Überlegenheit gegenüber dem bisher praktizierten Standardverfahren kontrovers diskutiert $[7,38,39]$. Eine Erniedrigung des im Blut gemessenen Fbg-/CRPQuotienten korrelierte allerdings mit dem Anstieg der Mortalität (all-cause Mortalität [40]). Gleiches wurde auch bei einem erniedrigten $\mathrm{Hb}-$ Wert $(<13 \mathrm{~g} / \mathrm{dl}$ ) beobachtet [41].

BNP (B-type natriuretic peptide) ist ein 32-Aminosäuren umfassendes Peptid, das vor allem in beiden Herzkammern freigesetzt wird. Die inaktive Form (Nt-proBNP $=\mathrm{N}$-terminales Frament) wird für die Diagnostik verwendet und verbessert zusammen mit den schon bekannten kardialen Risikofaktoren die Prognoseabschätzung bei einer Herzinsuffizienz und die der Risikostatifikation nach einem akuten Koronarsyndrom [42-46]. BNP hat eine Fülle von physiologischen Aufgaben, so u.a. den Natriumhaushalt, die Diurese und es wirkt vasodilatatorisch. Unter anderem wirkt die myokardiale Dehnung als Stimulus zur BNP-Freisetzung, weswegen erhöhte BNP-Plasmaspiegel bei der Herzinsuffizienz, aber auch bei einer Erhöhung des rechtsventrikulären Drucks gemessen werden [46-48]. Bei der COPD-Exazerbation lagen die BNP-Spiegel im Mittel um ca. $1 / 3$ höher als in der anschließenden Erholungsphase (65 pg/ml vs. 45 pg/ml, p <0,001). Intensivpflichtige Patienten wiesen sogar noch höhere BNP-Werte auf $(105 \mathrm{pg} / \mathrm{ml})$ und besaßen damit einen schwach positiven prädiktiven Wert für die Intensivpflichtigkeit (HR 1,13; 95\%Konfidenzintervall 1,03-1,24, ab BNP $100 \mathrm{pg} / \mathrm{ml}, \mathrm{p}=0,008$ ), nicht aber für ein erhöhtes Mortalitätsrisiko [39]. Pathophysiologisch wird als Ursache für die BNP-Erhöhung eine hypoxiebedingte Kontraktion der Pulmonalarterien mit konsekutiver Steigerung des rechtsventrikulären Drucks angenommen [39], obwohl bei der Exazerbation auch eine begleitende linksventrikuläre diastolische Funktionsstörung mit valvulärer Dysfunktion und in der Folge eine Rechtsherzbelastung in Frage kommen könnten $[49,50]$. Der BNP-Wert erlaubt eine Differenzierung, ob bei einer geklagten Dyspnoe primär eine dekompensierte Herzinsuffizienz oder eine pulmonale Ursache zugrunde liegt, da eine Herzerkrankung mit sehr hohen Werten (im Mittel 731 pg/ml) einhergeht. Sie erlauben aber keine Unterscheidung, ob sie durch eine primär kardiale Erkrankung oder bei pulmonalen Erkrankungen mit sekundärer Herzbelastung erhöht gemessen wurden. Die hohe Streubreite dieser Werte weist darauf hin, dass auch der 


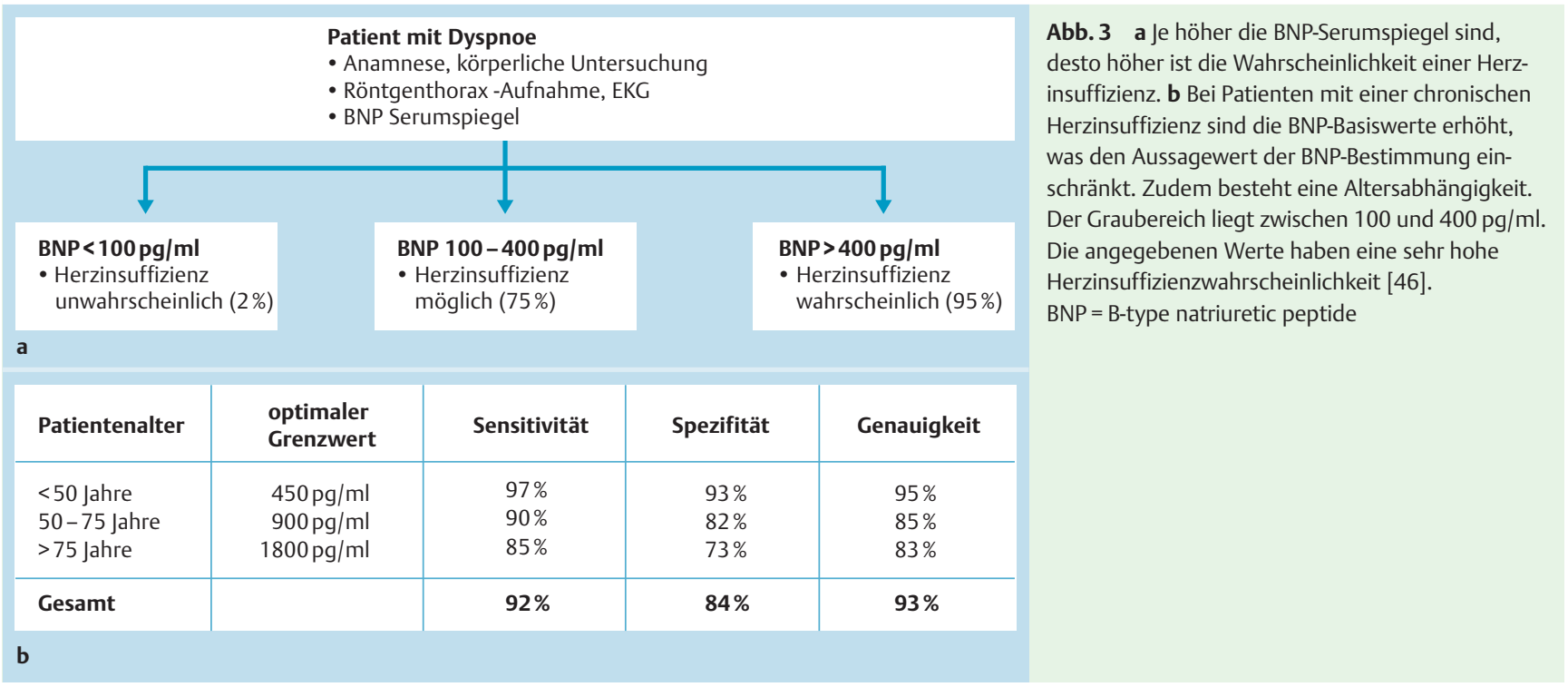

BNP-Wert die Standarddiagnostik nur unterstützt $[46,51]$. - Abb. 3 gibt eine konkrete diagnostische Abschätzung der Werte in der Herzinsuffizienzdiagnostik.

Zusammenfassend ist es auch mit Plasma-Biomarkern bei der COPD nicht möglich, den Erkrankungszustand (Schwere) auf verlässliche Art und Weise näher zu charakterisieren. Sie erlauben für den individuellen Patienten keine verlässliche prognostische Aussage über die weitere Erkrankungsentwicklung bzw. die Notwendigkeit der Einleitung oder des Absetzens bestimmter Therapien, auch wenn einzelne Studien auf eine solche Möglichkeit hindeuten [52]. Erhöhte BNP-Serumwerte weisen lediglich auf eine gleichzeitige Herzbelastung hin.

\section{Alpha-1-Antitrypsin-Mangel}

Im Gegensatz zur COPD wird der autosomal dominant vererbte Alpha-1-Antitrypsin-Mangel mittels aus dem Blut bestimmbarer Parameter gesichert, auf denen die Indikation zur Substitutionstherapie basiert $[53,54]$. Bei symptomatischen Patienten im Alter von unter 45 Jahren mit einem Lungenemphysem (FEV1 < 65\% des Sollwertes, FEV1-Abfall/Jahr $>120 \mathrm{ml}$ bei FEV1 > 65\% vom Sollwert) oder bei Neugeborenen, Kindern und älteren Erwachsenen mit Lebererkrankungen unklarer Genese oder einer Alpha-1-Antitrypsin-Mangelkrankheit in der Familie sollten die folgenden Tests durchgeführt werden [53,55-57]:

- Plasma-Protein-Elektrophorese: Bei einem Alpha-1-Antitrypsinmangel ist die alpha1-Globulinfraktion erniedrigt. Im positiven Fall

- Quantifizierung des Alpha-1-Antitrypsin-Serumspiegels, der im positiven Fall $<40 \%$ des Sollwertes (radiale Immundiffusion < $80 \mathrm{mg} / \mathrm{dl}$, Nephelometrie $50 \mathrm{mg} / \mathrm{dl} ; 11 \mu \mathrm{M}$ ) betragen würde. Im positiven Fall ist eine

- Phänotypisierung mittels isoelektrischer Fokussierung aus dem Serum empfohlen, der im positiven Fall einen Phänotyp PiZ oder PiSZ zeigt.

- Die Genotypisierung ist nur bei speziellen Fragestellungen notwendig.

Ferner müssen bei diesen Patienten ein IgA-Mangel, ein fortgesetzter Nikotinabusus (Nachweis mittels HbCO, Urin-Cotinin), ein dekompensiertes Cor pulmonale und eine Unverträglichkeit gegenüber Blutprodukten ausgeschlossen werden, da dies Aus- schlusskriterien für eine Alpha-1-Antitrypsin-Substitutionstherapie sind.

\section{Asthma bronchiale \\ $\nabla$}

\section{Sputum}

Die eosinophilen Granulozyten und das ECP sind in $80 \%$ aller steroidnaiven Asthmatiker im Vergleich zu gesunden Kontrollen erhöht. Die Sputum-Eosinophilenzahl korreliert mit der Asthmaschwere, der bronchialen Hyperreagibilität, der Peakflow-Variabilität und der Schwere der Asthma-Symptomen-Scores [58]. Bei Asthmapatienten mit einer Allergie führt die Inhalation eines Allergens zu einem Anstieg der Sputum-Eosinophilenzahl, die sich therapeutisch durch eine inhalative Kortikosteroidtherapie senken lässt. Ein Absetzen einer Kortikosteroidbehandlung führt wieder zu einem Anstieg der Sputum-Eosinophilenmenge. Parallel zu den Eosinophilenzahlen steigen die Sputumkonzentrationen von IL-5 (für Eosinophile ein chemotaktisch wirksames Interleukin), MPO, TNF- $\alpha$, ECP und andere an $[59,60]$.

Hohe Eosinophilenzahlen im Sputum sind prädiktiv für eine Zunahme von Asthmasymptomen und gehäuften Exazerbationen nach Reduktion oder Absetzen inhalativer Kortikosteroide. Umgekehrt zeigen absinkende Eosinophilenzahlen den Therapieerfolg einer inhalativen Kortikosteroidtherapie mit Reduktion der Exazerbationsrate und asthmabedingter Krankenhausaufnahmen an [61]. Die Diskriminierung zwischen COPD und Asthma ist anhand der Eosinophilenzahlen im Regelfall möglich, wird allerdings in seiner Aussagekraft dadurch eingeschränkt, dass auch COPD-Patienten eine erhöhte Eosinophilenanzahl im Sputum und in der BAL aufweisen können. Eosinophile im Sputum und in der BAL sind bei der COPD mit einem guten Therapieansprechen im Sinne einer höheren Verbesserung der FEV1 unter inhalativen Kortikosteroiden assoziiert als bei Patienten, bei denen im Sputum ein hoher Neutrophilenanteil dominiert [62 -67].

\section{Bronchialschleimhautbiopsie}

Biopsien der Bronchialschleimhaut imponieren bei steroidnaiven Patienten durch vermehrte eosinophile Granulozyten, Lymphozyten und Mastzellen im subepithelialen Gewebe sowie der Verbreiterung der Basalmembran und der inflammatorischen Schädigung der Bronchialepithelschicht, die Abschilferung. Umge- 


\begin{tabular}{|llllll|}
\hline Körpergröße & Alter & & & \\
& $\mathbf{2 5 - 3 4}$ Jahre & $\mathbf{3 5 - 4 4}$ Jahre & $\mathbf{4 5 - 5 4}$ Jahre & $\mathbf{5 5 - 6 4}$ Jahre & $\mathbf{6 5 - 7 5 ~ J a h r e ~}$ \\
\hline$<160 \mathbf{c m}$ & 24,0 & 24,5 & 28,8 & 31,5 & 34,1 \\
\hline $160-169 \mathrm{~cm}$ & 27,4 & 29,7 & 32,8 & 35,9 & 38,9 \\
\hline $170-179 \mathrm{~cm}$ & 31,2 & 34,1 & 37,3 & 40,9 & 44,3 \\
\hline $180-189 \mathrm{~cm}$ & 35,5 & 38,9 & 42,5 & 46,5 & 50,4 \\
\hline$>190 \mathrm{~cm}$ & 40,4 & 44,3 & 48,4 & 53,0 & 57,4 \\
\hline
\end{tabular}

Tab. 1 Obere FeNO-Grenzwerte (ppb), die an 1803 gesunden Nichtrauchern erhoben wurden [79]. kehrt konnte bei einem solchen Befund der restitutive Effekt einer inhalativen Kortikosteroidtherapie in eine post-therapeutische Folgebiopsie eindrucksvoll belegt werden [68]. Bioptischen Verfahren beim Asthma kommen in praxi weder eine diagnostische noch prognostische Bedeutung zu, auch wenn in Medikamentenstudien der Therapieerfolg eines Medikaments mittels Bronchialschleimhautbiopsie als Surrogatparameter eindrucksvoll belegt wurde [69].

Zusammenfassend haben in der Routinediagnostik des Asthmas weder die Sputumuntersuchungen noch auf bronchoskopischen Verfahren basierenden Untersuchungen einen Stellenwert, auch wenn in Studien der Therapieerfolg von z.B. einer inhalativen Kortikosteroidtherapie mittels Reduktion von Entzündungszellen und/oder Entzündungsmediatoren in der Bronchialschleimhautbiopsie, in der BAL oder im Sputum nachgewiesen wurde. Die gute mittels klinischer Evaluation und Lungenfunktion mögliche Therapiesteuerung rechtfertigt die genannten methodisch aufwendigen Verfahren allenfalls für wissenschaftliche Fragestellungen.

\section{FeNO}

In unbehandelten Asthmapatienten ist das ausgeatmete Stickstoffmonoxid (FeNO) erhöht und korreliert mit der Eosinophileninflammation der Atemwege atopischer (Asthma-) Patienten. FeNO-Konzentrationen korrelieren ferner mit dem Ausmaß der bronchialen Hyperreagibilität, der Reversibilität auf einen Bronchodilatator, der Positivität eines Allergen-Haut-Pricktests, Serum-IgE-Spiegel und Bluteosinophilenmenge. Nicht allergische Asthmapatienten weisen gegenüber Gesunden allerdings einen nur marginal erhöhten FeNO-Wert auf. Die Allergie ist somit die FeNO beeinflussende Erkrankung und weniger das Asthma [70-72].

Sinkende FeNO-Werte zeigen die Effektivität einer antiinflammatorischen Medikation an, da eine erfolgreiche inhalative Kortikosteroidtherapie mit Reduktion der bronchialen Entzündung auch die FeNO-Werte reduziert. Allerdings zeigen Studien, in denen die Effektivität der Therapiekontrolle zwischen FeNO und der Lungenfunktion/klinische Untersuchung miteinander verglichen wurde, dass die mittels FeNO geführten Patienten statistisch gegenüber den mittels Lungenfunktion geführten Patienten therapeutisch nicht überlegen sind [73,74]. Ganz im Gegenteil erhöhte sich sogar der inhalative Kortikosteroidverbrauch, ohne dass sich die Lungenfunktion zusätzlich verbesserte, weswegen die FeNO-gesteuerte Therapie wahrscheinlich sogar eine Übertherapie bewirkt $[74,75]$. Damit eignet sich FeNO allenfalls nur bedingt zur Therapiesteuerung, obwohl erhöhte Werte mit einem erhöhten Asthmaexazerbationsrisiko assoziiert wurden [75].

Wegen der zahlreichen Einflussfaktoren und der intraindividuellen Schwankungsbreiten gibt es derzeit keine allgemein anerkannten Referenzwerte, obwohl verschiedene Versuche unternommen wurden, solche zu erstellen. Wesentliche Einflussfakto- ren sind: Art der Erkrankung, Atemtechnik (Ausatemfluss), Patientenalter, Körpergröße, Geschlecht, Atopiestatus und Raucherstatus [27,29,30,75-78]. Das Ausmaß dieser Einflussfaktoren auf die FeNO-Messwerte wurde aber in Studien unterschiedlich bewertet. Olin et al. erstellten an 1131 gesunden Nichtrauchern Normwerte für FeNO ( $\bullet$ Tab. 1), die auf den empfohlenen Ausatemfluss von $50 \mathrm{ml} /$ Sekunde [28] normiert wurden [79].

Basierend auf diesem nicht allergischen Normalkollektiv ergibt sich folgende FeNO-Normalwerteformel:

FeNO $=-0,0026+0,013 \times$ Körpergröße $(\mathrm{cm})+0,01 \times$ Patientenalter (Jahre)

\section{Biomarker im Blut}

Wie auch im Sputum, in der BAL und in den Bronchialschleimhautbiopsien so findet sich auch im Blut von Asthmapatienten eine erhöhte Eosinophilenzahl. Die Behandlung mit Kortikosteroiden führt zu einer Reduktion der Eosinophilenzahl, des ECP und des EPO [80]. Bei Asthmatikern wurden im Blut zudem erhöht gefunden: Eotaxin, IL-4, IL-5, CCR-4, Ligand, TARC und MCP-4 [81 - 83]. Bei Allergikern ist zudem der Serum-IgE-Spiegel erhöht, der bei Asthmapatienten des Schwergrades IV für die Indikation einer Omalizumab-Behandlung mit entscheidend ist. Hohe Serum-IgE-Spiegel und eine erhöhte Eosinophilenzahl im Blut sind typisch für das allergische Asthma, welches somit gut von einer COPD unterschieden werden kann [84].

\section{Pneumonie \\ $\nabla$}

Bakterielle Infektionen und Sepsis sind die häufigsten Ursachen von Morbidität und Mortalität bei intensivpflichtigen internistischen Krankheitsbildern, wobei die ambulant erworbene Pneumonie $(\mathrm{CAP}=$ community aquired pneumonia) altersabhängig mit einer Inzidenz von 1,6 - 10,6 / 1000 Erwachsenen die am häufigsten zum Tode führende Infektionskrankheit darstellt. Eine schnelle und richtige Diagnosestellung sowie eine leitliniengerechte Therapie und Therapiesteuerung verbessert die Prognose dieser Patienten [15, 85-88]. Ein Therapieversagen stellt bei diesen Patienten einen unabhängigen Risikofaktor für eine erhöhte Mortalität dar, wie die CAPNETZ-Studie (German competence network for community-acquired pneumonia) zeigte [89]. Daher sind gerade bei diesen Patienten die individuelle Risikoabschätzung und die zeitnahe Therapieüberprüfung auch mit Hilfe von Biomarkern wichtig. Die wichtigsten klinischen Indizes sind vor allem die im CRB-65 Index subsumierten Parameter (confusion, respiratory rate [ $\geq 30$ Atemzüge/Minute], low blood pressure [systolisch $<90$, diastolisch $\leq 60 \mathrm{~mm} \mathrm{Hg}$ ], age [ $\geq 65$ Jahre]). Dem gegenüber stehen eine Fülle von im Blut quantifizierbaren Parametern, die einzeln oder kombiniert in der Diagnostik, Therapiesteuerung und/oder zur Prognoseabschätzung infektiöser Erkrankungen der Lunge und bei Sepsis Anwendung fanden bzw. finden: CRP, Leukozytenmenge, Procalcitonin (PCT), Zytokine 
und deren Rezeptoren (z.B. IL-1 $\beta$, TNF- $\alpha$, IL-6, IL-8), pro-endothelin-1, pro-Adrenomedullin, Nitrit, RBEF (pre-B-cell colony enhancing factor), CXC Chemokine, Surfactantproteine, sTREM-1 (soluble triggering receptor expressed on myeloid cells -1 ), suPAR (soluble urokinase-type plasminogen activator receptor), MIF (cytokine macrophage migration inhibitory factor), Wachstumsfaktoren (prostaglandin derived growth factor [PDGF], colony stimulating factor [CSF] tissue growth factor [TGF]), Lipopolysaccharid bindendes Protein (LBP), metabolische Marker (z.B. Colsterin) und BNP oder Quotienten zweier verschiedener Marker (z.B. IL-6/TNF $\alpha$ ) [90-97].

Marker mit der bei der Pneumonie höchsten Wertigkeit für Prognose und Therapiesteuerung sind PCT, CRP und Leukozytenmenge [95]. In der CAPNETZ-Studie lagen bei den 70 (4,2\%) verstorbenen CAP-Patienten die PCT-Plasmaspiegel signifikant über denen derer, die in dem 28-tägigen Beobachtungszeitraum nicht verstarben. PCT korrelierte ferner mit der Erkrankungsschwere und hatte einen mit dem CRB-65-Index vergleichbaren Vorhersagewert. Die prognostische Wertigkeit von CRP und Leukozytenhöhe lag dagegen im Vergleich signifikant niedriger [90]. Die PCT-kontrollierte Therapie, in der erst ab einem Plasmaspiegel $\geq 0,25 \mu \mathrm{g} / \mathrm{l}$ Antibiotika erlaubt waren, führte im Vergleich zum Standardvorgehen zu einer Reduktion der Verschreibungsrate von $72 \%$, bei einem jedoch vergleichbaren Therapieerfolg [98]. In einer anderen Studie konnte unter einer PCT-Therapiesteuerung der Antibiotikaverbrauch bei Patienten mit entweder einer CAP, einer COPD, einem Asthma oder anderen Infektionen der Atemwege und der Lunge um ca. $50 \%$ gesenkt werden, ohne dass es zu einer Verschlechterung des klinischen Erfolges kam [99]. Bei an einer Sepsis verstorbenen Patienten lag der PCTWert signifikant über den Werten derjenigen, die überlebten $(19,2$ vs. $2,4 \mathrm{ng} / \mathrm{ml}, \mathrm{p}=0,001)$. Etwas weniger deutlich fielen die entsprechenden Unterschiede der Plasma-sTREM-Werte aus (Verstorbene $94 \mathrm{pg} / \mathrm{ml}$ vs Überlebende $154 \mathrm{pg} / \mathrm{ml}, \mathrm{p}=0,02$ ) [92]. CRP diskriminierte nicht zwischen diesen beiden Gruppen.

Für die Entscheidung für oder gegen eine Antibiotikatherapie bei einer Infektion der unteren Atemwege wurden folgende PCTGrenzwerte vorgeschlagen [96-98]:

- $\mathrm{PCT}<0,1 \mu \mathrm{g} / \mathrm{l}$ : keine Antibiotika

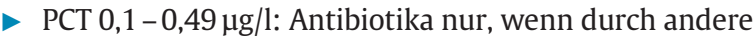
Befunde begründbar

- $\mathrm{PCP} \geq 0,5 \mu \mathrm{g} / \mathrm{l}:$ Antibiotikatherapie

Gründe für falsch zu hohe, z. B. bei akuter Niereninsuffizienz oder nicht bakteriellen Infektionen, oder falsch zu niedrige Werte, z. B. sehr frühe oder lokalisierte Entzündungsprozesse, sind dabei allerdings zu beachten [100].

Je nach Studie und Erkrankung korrelieren auch die anderen der o.g. zahlreichen Surrogatparameter mehr oder weniger mit dem Erkrankungsstatus der Hospital-Pneumonie (HAP =hospital aquired pneumonia), der Sepsis, aber auch der CAP sowie dem Therapieerfolg und ermöglichen einen Einblick in die zugrunde liegende Pathophysiologie des Entzündungsgeschehens. Manche haben alleine oder in Kombination mit den klinischen Parametern einen prognostischen Aussagewert. So zeigt z.B. ein hoher PSI (pneumonia severity index; PSI) in Kombination mit erhöhten BNP-Werten $(>279 \mathrm{pg} / \mathrm{ml}$ ) ein erhöhtes Risiko an, an einer CAP zu versterben oder ein Therapieversagen besser an, als die jeweiligen Parameter alleine [93]. Trotz dieser und anderer positiver Publikationen erlangten die meisten dieser Marker gegenüber den ohnehin zur Verfügung stehenden klinischen Parametern (s.o.; aber auch Beatmungsparameter, Körpertemperatur, radiologische Bildgebung) keine nennenswerte Bedeutung im täglichen Management der betroffenen Patienten [91,101]. Etabliert sind CRP, Leukozytenmenge und vor allem PCT.

\section{Tuberkulose}

Die jetzt zur Verfügung stehenden Interferon- $\gamma$-Tests beruhen auf aus dem Patientenblut isolierten Lymphozyten, die in vitro mit Tuberkuloseoberflächenantigen exponiert werden. Das von diesen Zellen freigesetzte Interferon- $\gamma$ wird in einem Immunoassay quantifiziert. Lymphozyten von Patienten, die mit diesen Tuberkuloseantigenen Kontakt hatten, weisen typischerweise eine erhöhte Interferon- $\gamma$-Freisetzung auf. Es wird somit die zellvermittelte Immunantwort gegen drei Tuberkulose-Antigene bestimmt. Die Indikationen für diesen Test sind [102]:

1. Diagnostik einer Mycobacterium tuberculosis Infektion

(aktiv und latent)

2. Screening von Kontaktpersonen

3. Ausschluss einer latenten Tuberkuloseinfektion, z. B. bei

Patienten, die mit Immunsuppressiva oder TNF $\alpha$-Antikörpern therapiert werden müssen.

Der Interferon- $\gamma$-Test besitzt die Vorteile, dass keine Kreuzreaktion mit einer BCG-Impfung oder nicht tuberkulösen Mykobakterien auftreten und dass er mit einer Spezifität von bis $z u \geq 95 \%$ und einer Sensitivität von $\geq 90 \%$ für eine aktive oder latente Tuberkuloseinfektion spezifischer und sensitiver als der Tuberkulin-Hauttest (Hauttest $<70 \%$ ) ist [103]. Vorausgesetzt, es liegt kein Immundefekt vor, schließt ein negativer Test durch die fehlende Immunreaktion gegenüber Tbc-Antigenen eine stattgehabte Tuberkulose praktisch aus. Ein negativer Interferon- $\gamma$-Test bei positivem Tuberkulin-Hauttest könnte für eine latente Tuberkulose sprechen $[104,105]$. Allerdings ergeben sich auch einige Einschränkungen. So erlaubt der Test keine Aussage zur Aktivität, d.h. es kann nicht zwischen einer latenten Infektion und einer aktiven Tuberkulose unterschieden werden. Bei Lymphopenie, angeborenen oder erworbenen Immundefekten einschließlich HIV und medikamentöser Immunsuppression sowie bei Kindern unter 2 Jahren ist die Sensitivität des Tests herabgesetzt [106]. Unverändert gilt für den Tuberkulosenachweis das kulturelle Ergebnis als der diagnostische Goldstandard. Der Interferon- $\gamma$-Test ersetzt nicht die anderen bei der Tuberkulosediagnostik erforderlichen Untersuchungen, wie z.B. die radiologische Bildgebung, die Mikrobiologie, sondern unterstützt diese [107,108]. Der Test ist nicht zum Nachweis der nicht tuberkulösen Mykobakteriose geeignet.

Ungeachtet dieser Testverfahren wird die aktive Infektion mittels mikroskopischen Nachweises säurefester Stäbchen, z. B. im Sputum oder in der Biopsie ( Abb.4), und dem kulturellen Nachweis geführt [109].

Erst im positiven Fall ergibt sich die Indikation zur antituberkulösen Therapie [107,110].

\section{Interstitielle Lungenerkrankungen}

$\nabla$

Über 2000 verschiedene interstitielle Lungenerkrankungen (diffuse parenchymale Lungenerkrankungen DPLDs) oder extrapulmonale Erkrankungen (z.B. Sklerodermie, granulomatöse Erkrankungen, Erkrankungen aus dem rheumatischen oder dem autoimmunologischen Formenkreis) sind bekannt, die zu einer direkten oder indirekten Entzündung des Lungenparenchyms führen. Des Weiteren können auch diverse Medikamente (z.B. 


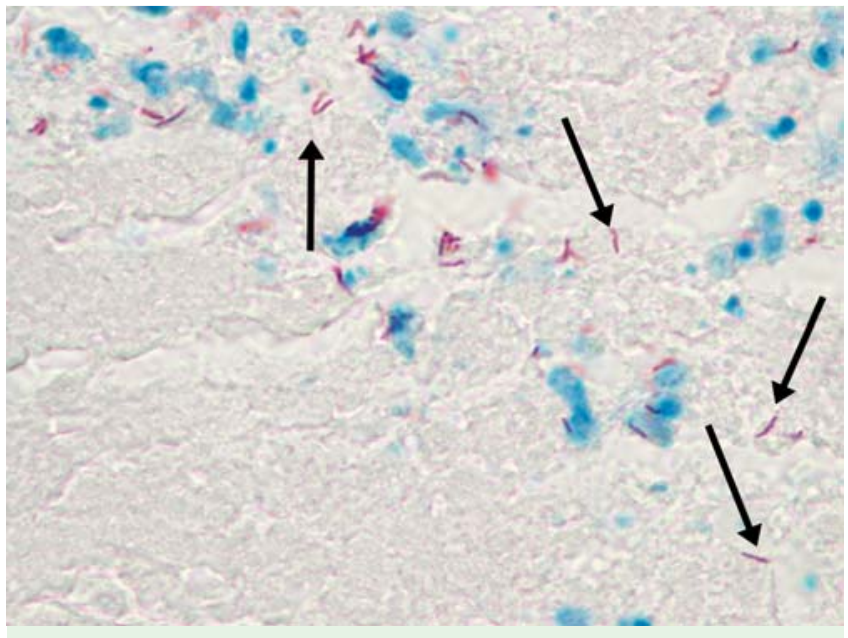

Abb. 4 Käsige Nekrose einer Lungentuberkulose mit Zellresten (blau) und säurefesten Stäbchenbakterien (Mykobacterium tuberculosis, Pfeile); ZiehlNeelsen, $\times 250$.

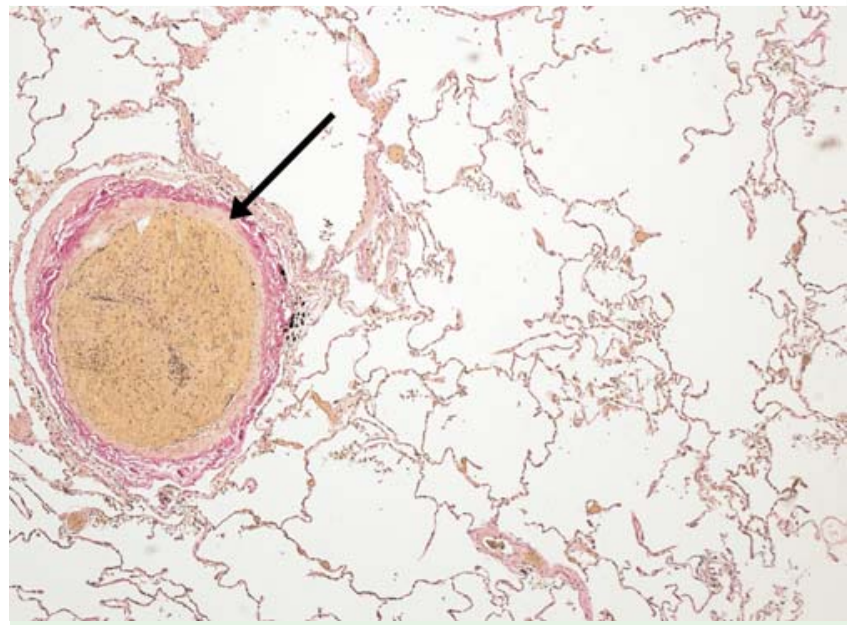

Abb. 5 Verschluss eines Pulmonalarterienastes (links) durch einen Thrombembolus (Pfeil) umgeben von einem panacinären Emphysem; v. Gieson, $\times 10$.
Amiadaron, einige Immunsuppressiva) oder Stäube (z. B. Asbest, Byrillium) zu einer interstitiellen Lungenentzündung führen [111 - 113]. Bei vielen dieser Erkrankungen ist die Ätiologie nicht bekannt [114-116]. Die Diagnosestellung beruht auf der Anamnese, dem HRCT (high resolution Computertomographie) der Lunge, der Lungenfunktionsprüfung und bei unklaren Fällen auf einer Lungenhistologie $[117,118]$.

Bei immunologisch ausgelösten DPLDs, insbesondere die Hypersensitivitätspneumonitis (HP; z.B. Farmerlunge), helfen die im Blut bestimmbaren Antigentiter, das auslösende Agens einzugrenzen bzw. zu beweisen und haben neben dem Nachweis einer aktuellen Antigenexposition, rezidivierenden Symptomen, Fibroseknistern bei der Auskultation, Auftreten von Symptomen 4-6 Stunden nach Antigenexposition und Gewichtsverlust einen hohen prädiktiven Wert für eine klinische Verschlechterung (OR 5,3, 95\% CI 2,7-10,4) [119]. In der Vergangenheit wurde auch bei anderen DPLDs Biomarker im Blut untersucht. Bei der Sarkoidose korrelieren z.B. der erhöhte lösliche IL-2-Rezeptor und Neopterin mit der Schwere der Sarkoidose [120]. Symptomatische Sarkoidose-Patienten weisen vergleichbar erhöhte Serum-ACE (angiotensin converting enzyme)-Spiegel auf, die mit einer Erhöhung des Propeptids des Typ-I-Prokollagens in der BAL korrelierten [121]. Eine ACE-Serumerhöhung ist aber nicht für eine Sarkoidose beweisend. Bei der IPF wurde ACE-2 dagegen eine prädiktive Funktion zugeschrieben [122]. Weitere bzgl. einer prognostischen und diagnostischen Wertigkeit untersuchte Serummarker waren z.B. Metalloproteinasen, Oxidantien und Oxidationsprodukte, Antioxidantien, Serum-KL-6 (MUC1 mucin), Surfactantprotein-A und -D, Laktatdehydrogenase, CYFRA-16 (Cytokeratin-19), Zytokeratin-18 und anti-Zytokeratin-18 Antikörperimmunkomplexe oder MCP-1 (monocyte chemoattractant protein-1) [123, 124, 125-127].

Das Ergebnis der BAL hat in der Diagnostik interstitieller Lungenerkrankungen nur unterstützenden Wert. Einen prädiktiven Wert besitzt sie nicht, hat aber unser pathophysiologisches Verständnis der untersuchten Erkrankungen vertieft [117,128,129]. Es gibt bzgl. der DPLDs keinerlei Biomarker, die zum gegenwärtigen Zeitpunkt einen für die Praxis nennenswerten diagnostischen, therapeutischen oder prognostischen Wert besitzen. Ob in Zukunft die Analyse von Proteinnetzwerken (proteomics) weiterhilft, wie unlängst diskutiert, bleibt abzuwarten [130,131].

\section{Lungenembolie}

\section{$\nabla$}

Obwohl die meisten Patienten mit akuter Lungenembolie (LE) eine gute Prognose aufweisen, übersteigt die Gesamtmortalität nach 3 Monaten 15\%. Während der ersten 30 Tage nach Diagnosestellung stellt das akute Rechtsherzversagen die häufigste Todesursache dar und die spätere Mortalität ist oft durch zugrunde liegende Krankheiten wie Herzinsuffizienz, Tumorleiden oder chronische Lungenerkrankungen bedingt [132].

Die Risikostratifizierung ist nicht nur hilfreich, um die initiale Therapie festzulegen, sondern auch entscheidend für das Langzeit-Management. Ausgewählte Patienten können von der systemischen Thrombolyse oder der chirurgischen Embolektomie profitieren [133]. Die akkurate Risikoeinschätzung hilft auch diejenigen Patienten zu identifizieren, die ein erhöhtes Risiko der Entwicklung einer chronisch-thromboembolischen pulmonalen Hypertonie aufweisen.

Die Diagnosestellung und Risikostratifizierung der Lungenembolie umfasst folgende diagnostische Schritte [134]:

1. die klinische Beurteilung: klinische Zeichen der Rechtsherzbelastung, Hypotonie, Halsvenenstauung, Herztöne/pathologische Herzgeräusche infolge Trikuspidalinsuffizienz,

2. EKG: Tachykardie, T-Wellen-Inversion, Qr in V1,

3. Echokardiografie: Thrombennachweis (histologisches Korrelat in Abb. 5), Quantifizierung der Rechtsherzbelastung/ rechtsventriukärer Dysfunktion, Abklärung wichtiger Differentialdiagnosen (z. B. Aortendissektion, Perikardtamponade, offenes Foramen ovale),

4. CT des Thorax: Thrombennachweis ( $\bullet$ Abb. 6), Pneumonienachweis, Abklärung wichtiger Differenzialdiagnosen und

5. Biomarker [135]: D-Dimere, Troponin I und T, NT-pro brain natriuretic peptide (NT-proBNP) und BNP

Die Höhe des Troponin-Spiegels korreliert bei der akuten Lungenembolie mit dem Ausmaß der rechtsventrikulären Dysfunktion. Als Pathomechanismus der Troponin-Freisetzung wird eine Mikro-Myokardnekrose infolge eines Missverhältnisses zwischen dem erhöhten Sauerstoffbedarf des druckbelasteten rechten Ventrikels und dem aktuell geringen Sauerstoffangebot angenommen. Der negative prädiktive Wert für die Krankenhausmortalität bei niedrigen Troponinwerten beträgt 97\% [136]. 


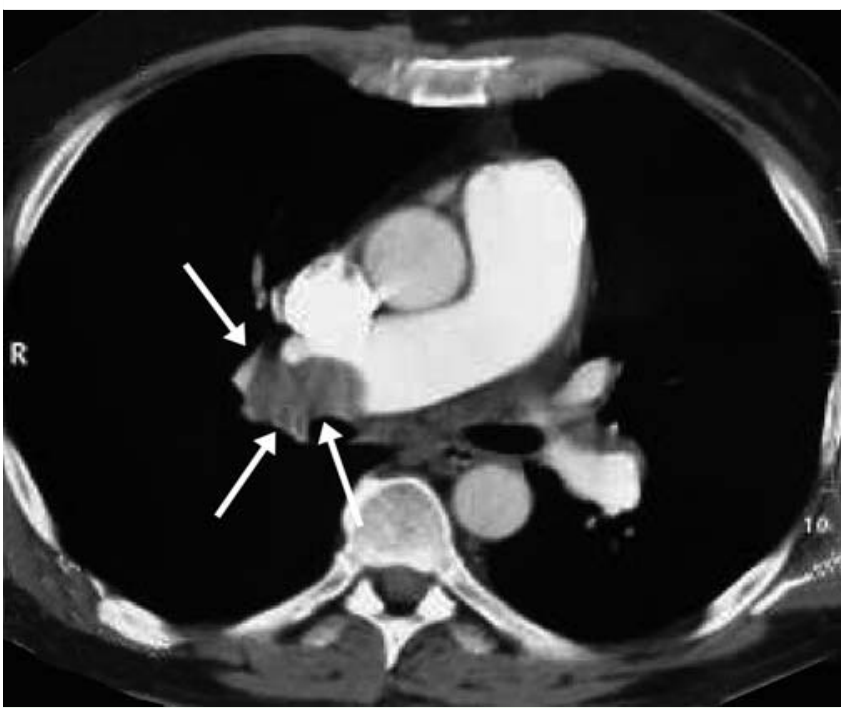

Abb. 6 Embolus in der A. pulmonalis (Pfeil).

Wie auch bei der COPD-Exazerbation erhöhen sich die Plasma NT-proBNP und BNP-Werte bei einer Rechtsherzbelastung. Erhöhte Plasmawerte sind mit einer gesteigerten Krankenhausmortalität assoziiert [137]. Der negative prädiktive Wert für die Krankenhausmortalität beträgt 99\% für die NT-proBNP und BNP, d.h. niedrige Werte schließen ein erhöhtes Risiko aus. Die cutoff-Werte liegen allerdings niedriger (z.B. BNP $50 \mathrm{pg} / \mathrm{ml}$ ) als die cut-off-Werte für die Herzinsuffizienz (z. B. BNP 90 pg/ml). Durch die möglichen kardialen, pulmonalen und vielen anderen Differenzialdiagnosen, wie z.B. Leukämien, Sepsis, Tumore (vor allem Ovarialkarzinom, Lungentumore), Komplikationen während der Schwangerschaft und selbst körperlicher Stress, haben erhöhte Messwerte für die Lungenembolie keine diagnostische Bedeutung [50].

Aus quervernetztem Fibrin spaltet Plasmin, unter der Wirkung von Faktor XIII, Dimere strangversetzter Bruchstücke des Fibrins $\mathrm{ab}$, sogenannte D-Dimere, welche die D und E Sequenz enthalten. Diese werden anschließend mit einer physiologischen Halbwertszeit von ca. $8 \mathrm{~h}$ weiter abgebaut [138]. Der Nachweis von D-Dimere erlaubt also keine Differenzierungsmöglichkeit bezüglich der Lokalisation des Thrombus, sondern zeigt lediglich eine Fibrinolyse und damit alle Krankheitszustände mit gesteigerter Gerinnungsaktivierung an. Negative D-Dimere schließen bei ent- sprechendem klinischen Verdacht eine Pulmonalembolie mit fast $100 \%$ iger Wahrscheinlichkeit aus. Dieser hohe negativ prädiktive Aussagewert hilft, in der Praxis eine aufwendige Lungenemboliediagnostik zu reduzieren [139]. Bei kleinen peripheren Pulmonalembolien ( $\bullet$ Abb. 5) sinkt die Sensitivität allerdings auf $70 \%$ [138].

Nordenholz et al. testeten bei Patienten mit einer Lungenembolie oder einer tiefen Beinvenenthrombose 50 weitere Biomarker und fanden, dass lediglich D-Dimere, CRP und die Myeloperoxidase (MPO) eine gewisse diagnostische Aussage für das Vorliegen einer Lungenembolie besitzen [140]. Bei einem Grenzwert von $\geq 500 \mathrm{ng} / \mathrm{ml}$ betrug die Sensitivität und Spezifität von D-Dimere für das Vorliegen einer Lungenembolie oder einer Venenthrombose $100 \%$, womit eine frühere Studie, die den gleichen Grenzwert untersuchte, bestätigt wurde [141]. Die Kombination negativer D-Dimere oder einem MPO-Wert von $<22 \mathrm{mg} / \mathrm{dl}$ nicht aber CRP sagten mit einer Sensitivität von 100\% und einer Spezifität von 73 \% ein negatives Ergebnis in der Pulmonalisangiografie voraus [142].

\section{Biomarker: ein kleiner Blick in die Zukunft} $\nabla$

Biomarker sind aus der medizinischen Diagnostik und zur besseren Therapiesteuerung nicht mehr wegzudenken. Manche besitzen einen prognostischen Wert. Die meisten Marker eignen sich allerdings als diagnostische und die Therapie leitende Surrogatparameter nicht, da Sensitivität und/oder Spezifität nicht beschrieben oder zu schlecht sind. Auch in der Pneumologie wird unverändert nach Surrogatparametern gesucht, die uns zusätzliche verlässlichere Aussagen über die Patienten ermöglichen und die eine hohe Korrelation mit den uns zur Verfügung stehenden diagnostischen Parametern besitzen ( $\bullet$ Abb. 7).

Wissenschaftlich interessant ist diesbezüglich die Entwicklung bei Parametern aus der Ausatemluft und dem Atemkondensat.

\section{Atemkondensat}

Aus diversen methodischen Gründen hat sich die Hoffnung, durch die Bestimmung von Atemkondensatmarkern eine genauere Diagnostik und therapeutische Erfolgskontrolle bei entzündlichen, allergischen, malignen, degenerativen und durch Umwelteinflüsse bedingten Atemwegs- und Lungenerkrankungen zu erzielen, bis heute nicht erfüllt $[27,143,144]$. Folgende Ansätze werden zur Zeit in wissenschaftlichen Studien verfolgt:

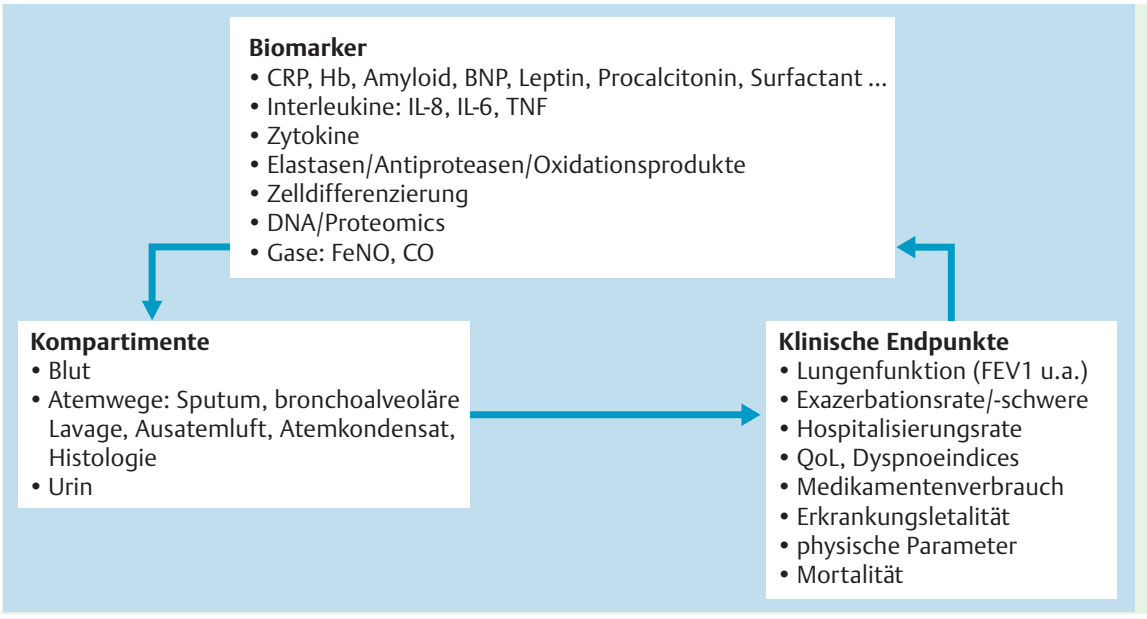

Abb. 7 Auswahl von Biomarkern, deren Beziehung zur Quelle und dem Bezug zur Klinik. QoL = Lebensqualitätsfragebogen (quality of life questionnaire), IL- = Internleukine, FeNO = exhaliertes Stickstoffmonoxid, $\mathrm{CO}=$ Kohlenmonoxid. 
- Proteine: Die Erstellung von Proteinprofilen (proteomics) ermöglicht auf der translationalen Seite die Untersuchung von Proteinnetzwerken, wie sich diese im Zellmetabolismus und letztendlich auf die Entstehung von Krankheiten auswirken. Die Charakterisierung von Proteinnetzwerken im einfach zu gewinnenden Atemkondensat, aber auch im Sputum oder in der BAL böte sich als Methode zur Erweiterung unseres pathophysiologischen Verständnisses von benignen und malignen Atemwegs- und Lungenerkrankungen und/oder zur Diagnostik an [145-147].

- DNA-Mikrosatelliten (MSs): MSs sind die häufigsten intergenetischen DNA-Sequenzen, die sich im eukariontischen Genom als minimal repetitive Sequenzen (meist ein bis fünf Basenpaare) wiederholen. Da das Ausmaß der MSs-Instablität mit hohen Genmutationsraten korreliert, eignen sie sich zur Identifizierung von sich potenziell verändernden Genregionen $[148,149]$. Im Exhalat gemessene MSs-Instabiltät lag bei Patienten mit einem Asthma, einer COPD oder malignen Erkrankungen im Vergleich zu Gesunden höher $[150,151]$.

\section{Elektronische Nase}

Die s.g. elektronische Nase bildet basierend auf elektronischen Signalen einen digitalen Fingerabdruck der in der Luft enthaltenen Moleküle. Die elektrische Signalstärke von mehreren Sensoren (Sensor- oder Chemosensor-Arrays) wird mathematisch verarbeitet und als Mustererkennung wiedergegeben. Einzelne Stoffe oder Stoffgruppen können nicht erkannt werden, sondern nur Muster der molekularen Zusammensetzung der analysierten Luft oder volatile organic compunds (VOCs). Die VOCs der exhalierten Luft kann bei bestimmten Erkrankungen ein charakteristisches Muster aufweisen und so z.B. auf ein Malignom oder ein Asthma hinweisen [152 - 155]. Die Messung ist simpel, da der Patient lediglich in ein Gerät einatmen muss, das je nach Hersteller nur die Größe einer Flasche besitzt. Durch die fehlende Validierbarkeit, die Fülle an Einflussgrößen und die schwierige Interpretierbarkeit der Ergebnisse eignet sich diese Methode (noch) nicht für die Routine [156].

\section{Spektrometrie}

Spektrometrische Analysen erlauben die Quantifikation von Spurengasen und in der Luft befindlichen Komponenten/Molekülen [157]. Gaschromatographische Profile und die (massen-)spektrometrisch gemessenen exhalierten Moleküle, wie z. B. Methylfurane können zwischen aktiven, passiven und Nichtrauchern unterscheiden $[158,159]$. Wie auch bei der elektronischen Nase sind die methodischen Einflussgrößen groß. Durch die ausgesprochene Empfindlichkeit und Sensitivität ergeben sich aber auch Störfaktoren seitens des Patienten und der mitgemessenen Umgebungsluft, da kleinste Veränderungen das Detektionsmuster grundlegend ändern können, was auch für die ebenfalls in Entwicklung befindliche Nuklearmagnetresonanz-Messung gilt [21].

\section{Interessenkonflikte}

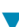

A. Gillissen, W. Wiechmann und U. R. Jürgens erklären, dass bezüglich des Artikelinhalts bei keinem ein Interessenkonflikt mit der pharmazeutischen Industrie oder sonstigen Dritten besteht.

\section{Literatur}

1 Cazzola M, MacNee W, Martinez FJ et al. Outcomes for COPD pharmacological trials: from lung function to biomarkers. Eur Respir J 2008; 31: $416-469$

2 Gillissen A, Bartling A, Rasche K. Bronchoalveoläre Lavage. Klinikarzt 1997; 26: 50-56

3 Stanescu D, Sanna A, Veriter C et al. Airways obstruction, chronic expectoration, and rapid decline of FEV1 in smokers are associated with increased levels of sputum neutrophils. Thorax 1996; 51: 267-271

4 Brightling $C E$, Monteiro $W$, Ward $R$ et al. Sputum eosinophilia and short-therm response to prednisolone in chronic obstructive pulmonary disease: a randomised controlled trial. Lancet 2008; 356: 1480 1485

5 Perng D-W, Huang H-Y, Chen H-M et al. Characteristics of airway inflammation and bronchodilator reversibility in COPD: a potential guide to treatment. Chest 2004; 126: 375-381

6 Gompertz S, O'Brien C, Bayley DL et al. Changes in bronchial inflammation during acute exacerbations of chronic bronchitis. Eur Respir J 2001; 17: $1112-1119$

7 Stolz D, Christ-Crain M, Morgenthaler NG et al. Copeptin, C-reactive protein and proclacitonin as prognostic biomarkers in acute exacerbation of COPD. Chest 2007; 131: 1058-1067

8 Magnussen $H$. COPD: eine entzündliche Erkrankung der Atemwege? Pneumologie 2004; 58: 320 - 324

9 Stockley RA, O'Brien C, Pye A, Hill SL. Relationship of sputum color to nature and outpatient management of acute exacerbations of COPD. Chest 2000; 117: 1638 - 1645

10 Papi A, Ballettato M, Braccioni F et al. Infections and airway inflammation in chronic obstructive pulmonary disease severe exacerbations. Am J Respir Crit Care Med 2006; 173: 1114 - 1121

11 Saetta M, Di Stefano A, Maestrelli P et al. Activated T-lymphocytes and macrophages in bronchial mucosa of subjects with chronic bronchitis. Am Rev Respir Dis 1993; 147: 301-306

12 Saetta M, Di Stefano A, Turato G et al. CD8 T-lymphocytes in peripheral airways of smokers with chronic obstructive pulmonary disease. Am J Respir Crit Care Med 1998; 157: 822 - 826

13 Schäfer H, Ewig S. Acute exacerbations in chronic obstructive pulmonary disease (COPD) - microbial patterns and risk factors. Monaldi Arch Chest Dis 2000; 55: 415-419

14 Eller J, Ede A, Schaberg T et al. Infective exazerbations of chronic obstructive pulmonary disease. Relation between bacteriologic etiology and lung function. Chest 1998; 113: 1542 - 1548

15 Höffken G, Lorenz J, Kern W et al. S3-Leitlinie zu Epidemiologie, Diagnostik, antimikrobieller Therapie und Management von erwachsenen Patienten mit ambulant erworbenen tiefen Atemwegsinfektion. Pneumologie 2005; 59: 612-664

16 GOLD Executive Committee. Global initiative for chronic obstructive lung disease. www.goldcopd.com; Stand: 2008

17 Vogelmeier C, Buhl R, Criee C-P et al. Leitlinie der Deutschen Atemwegsliga und der Deutschen Gesellschaft für Pneumologie und Beatmungsmedizin zur Diagnostik und Therapie von Patienten mit chronisch obstruktiver Bronchitis und Lungenemphysem (COPD). Pneumologie 2007; 61: e1 - e40

18 Hogg JC, Chu F, Utokaparch S et al. The nature of small-airway obstruction in chronic obstructive pulmonary disease. N Engl J Med 2004; 350: $2645-2653$

19 Saetta M. Airway inflammation in chronic obstructive pulmonary disease. Am J Respir Crit Care Med 1999; 160: 17-20

20 Yoshikawa T, Dent G, Ward J et al. Impaired neutrophil chemotaxis in chronic obstructive pulmonary disease. Am J Respir Crit Care Med 2007; $175: 473-479$

21 Borrill ZL, Roy K, Singh D. Exhaled breath condensate biomarkers in COPD. Eur Respir J 2008; 32: 472 - 486

22 Dalaveris E, Kerenidi T, Katsabeki-Katsafli A et al. VEGF, TNF-a and 8isoprostane levels in exhaled breath condensate and serum of patients with lung cancer. Lung Cancer 2008; 64: 219-225

23 Kharitonov SA, Barnes PJ. Exhaled biomarker. Chest 2006; 130: 1541 1546

24 Nowak D, Kasielski M, Antczak A et al. Increased content of thiobarbituric acid-reactive substances and hydrogen peroxide in the expired breath condensate of patients with stable chronic obstructive pulmonary disease: no significant effect of cigarette smoking. Respir Med 1999; 93: 389-396

25 Rahman I. Reproducibility of oxidative stress biomarkers in breath condensate: are they reliable? Eur Respir J 2004; 23: 183-184 
26 Hoydonck van PGA, Wuyts WA, Vanaudenaerde BM et al. Quantitative analysis of 8-isoprostane and hydrogen peroxide in exhaled breath condensate. Eur Respir J 2004; 23: 189 -192

27 Silkoff PE, Erzurum SC, Lundberg JO et al. Amercian Thoracic Society. ATS workshop proceedings: exhaled nitric oxide and nitric oxide oxidative metabolism in exhaled breath condensate. Proc Am Thorac Soc 2006; 3: 131 - 145

28 American Thoracic Society, European Respiratory Society. ATS/ERS recommendations of standardized procedures for the online and offline measurement of exhaled lower respiratory nitric oxide and nasal nitric oxide, 2005. Am J Respir Crit Care Med 2005; 171: 912 - 930

29 Kharitonov SA, Barnes PJ. Clincial aspects of exhaled nitric oxide. Eur Respir J 2000; 16: 781 - 792

30 Holz 0 , Jörres $R$. Nichtinvasive Verfahren zum Nachweis der Atemwegesentzündung im Vergleich. Kosten-Nutzen-Wertigkeit. Pneumologie $2004 ; 58: 510-515$

31 Jörres $R$. Modelling the production of nitric oxide within the human airways. Eur Respir J 2000; 16: 555-560

32 Barceló B, Pons J, Ferrer JM et al. Phenotypic characterisation of T-lymphocytes in COPD: abnormal CD4 + CD25 + regulatory T-lymphocyte response to tobacco smoking. Eur Respir J 2008; 31: 555-562

33 Smyth LJ, Starkey C, Vestbo J et al. CD4-regulatory cells in COPD patients. Chest 2007; 132: 156-163

34 Vassilakopoulos T, Hussain SN. Ventilatory muscle activation and inflammation: cytokines, reactive oxygen species, and nitric oxide. J Appl Physiol 2007; 102: 1687-1695

35 Walter RE, Wilk JB, Larson MG et al. Systemic inflammation and COPD. The Framingham Heart Study. Chest 2008; 133: 19-25

36 Bozinovski S, Hutchinson A, Thompson $M$ et al. Serum amyloid A is a biomarker of acute exacerbations of chronic obstructive pulmonary disease. Am J Respir Crit Care Med 2008; 177: 269 - 278

37 Karadog F, Karul AB, Cilag $O$ et al. Biomarkers of systemic inflammation in stable and exacerbation phases of COPD. Lung 2008; 186: 403 409

38 Daubin C, Parienti J-J, Vabret A et al. Procalcitonin levels in acute exacerbation of COPD admitted in ICU: a prospective cohort study. BMC Infect Dis 2008; 8: 145 -1471[-2334-8- I45]

39 Stolz D, Breidthardt T, Christ-Crain $M$ et al. Use of B-type natriuretic peptide in the risk stratification of acute exacerbations of COPD. Chest 2008; 133: 1088 - 1094

40 Man SFP, Xing L, Connett JE et al. Circulating fibronectin to C-reactive protein ratio and mortality: a biomarker in COPD? Eur Respir J 2008; 32: $1451-1457$

41 Cote C, Zilberberg MD, Mody SH et al. Haemoglobin level and its clinical impact in a cohort of patients with COPD. Eur Respir J 2007; 29: 923 - 929

42 Blankenberg S, McQueen MJ, Smieja M et al. Comparative impact of multiple biomarkers and N-terminal pro-brain natriuretic peptide in the context of conventional risk factors for the prediction of recurrent cardiovascular events in the heart outcomes prevention evaluation (HOPE) study. Circulation 2006; 114: $201-208$

43 Shlipak MG, Ix JH, Bibbins-Domingo $K$ et al. Biomarkers to predict recurrent cardiovascular disease: the heart and soul study. Am J Med 2008; $121: 50-57$

44 Pfisterer M, Buser P, Rickli H et al. BNP-guided vs symptom-guided heart failure therapy: the trials of intensified vs standard medical therapy in elderly patients with congestive heart failure (TIME-CHF) randomized trial. JAMA 2009; 301: 383 - 391

45 Myers GL, Christenson RH, Cushman M et al. National academy of clinical biochemistry laboratory medicine practice guidelines: emerging biomarkers for primary prevention of cardiovascular disease. Clin Chem 2009; 55: 378-384

46 Maisel A, Müller C, Adams KJr. et al. State of the art: using natriuretic peptide levels in clinical practice. Eur J Heart Fail 2008; 10: 824-839

47 Rutten FH, Cramer MJ, Zuithoff NP et al. Comparison of B-type natriuretic peptide assays for identifying heart failure in stable elderly patients with a clinical dignosis of chronic obstructive pulmonary disease. Eur J Heart Fail 2007; 9: 651 - 659

48 Arnold JMO, Howlett JG, Dorian P et al. Canadian Cardiovascular Society consensus conference recommendations on heart failure update 2007: prevention, management during intercurrent illness or acute cecompensation, and use of biomarkers. Can J Cardiol 2007; 23: 21 45

49 Ishii J, Nomura $M$, Ito $M$ et al. Plasma concentration of brain natriuretic peptide as a biochemical marker for the evaluation of right ventricular overload and mortality in chronic respiratory disease. Clin Chim Acta 2000; 301: 19-30

50 Müller C, Laule-Kilian K, Frana B et al. Use of B-type natriuretic peptide in the management of acute dyspnea in patients with pulmonary disease. Am Heart J 2006; 151: 471 - 477

51 Morrison LK, Harrison A, Krishnaswamy P et al. Utility of a rapid B-natriuretic peptide assays in differentiating congestive heart failure from lung diseases in patients presenting with dyspnea. J Am Coll Cardiol 2002; 39: 202 - 209

52 Snell $N$, Newbold $P$. The clinical utility of biomarkers in asthma and COPD. Curr Opin Pharmacol 2008; 8: 222-235

53 American Thoracic Society, European Respiratory Society. American Thoracic Society/European Respiratory Society statement: Standards for the diagnosis and management of individuals with alpha-1 antitrypsin deficiency. Am J Respir Crit Care Med 2003; 168: 818-900

54 Gillissen A, Schmidt EW, Rasche B et al. The biochemical behaviour of alpha1-antitrypsin under substitution therapy at homozygote (PI-ZZ) patients. Klin Wschr 1989; 67: 328-335

55 Köhnlein T, Welte T. Alpha-1 Antitrypsin-Mangel. 1. Ausg. Bremen, London, Boston: Uni-Med, 2003

56 Biedermann A, Köhnlein T. Alpha-1-Antitrypsin-Mangel - eine versteckte Ursache der COPD. Überblick über Pathogenese, Diagnostik, Klinik und Therapie. Dt Ärztebl 2006; 103: A1828 - A1832

57 Wencker M, Banik N, Buhl R et al. Long-term treatment of alpha-1 antitrypsin deficiency-related pulmonary emphysema with human alpha-1 antitrypsin. Eur Respir J 1998; 11: 428-433

58 Adachi T, Motojima S, Hirata A et al. Eosinophil viability-enhancing activity in sputum from patients with bronchial asthma. Contribution of interleukin-5 and granulocyte/macrophage colony-stimulating factor. Am J Respir Crit Care Med 1995; 151: 618 - 623

59 Green RH, Brightling CE, McKenna $S$ et al. Asthma exacerbations and sputum eosinophil counts: a randomized controlled trial. Lancet 2002; 360: 1715 - 1721

60 Jatakanon A, Lalloo UG, Lim S et al. Increased neutrophils and cytokines, TNF-alpha and IL-8, in induced sputum of non-asthmatic patients with chronic dry cough. Thorax 1999; 54: 234-237

61 Maneechotesuwan K, Essilfie-Quaye S, Kharitonov SA et al. Loss of control of asthma following inhaled corticosteroid withdrawal is associated with increased sputum interleukin- 8 and neutrophils. Chest 2007; 132: 98 - 105

62 Gibson PG, Fujimura M, Niimi A. Eosinophilic bronchitis: clinical manifestations and implications for treatment. Thorax 2002; 57: 178 182

63 Pizzichini E, Pizzichini MMM, Gibson P et al. Sputum eosinophilia predicts benefit from prednisone in smokers with chronic obstructive bronchitis. Am J Respir Crit Care Med 1998; 158: 1511 - 1517

64 Julius $P$, Hochheim D, Boser K et al. Interleukin-5 receptors on human lung eosinophiles after segmental allergen challenge. Clin Exp Allergy 2004; 34: $1064-1070$

65 Ohnishi T, Sur S, Collins DS et al. Eosinophil survival activity identified as interleukin-5 is associated with eosinophil recruitment and degranulation and lung injury twenty-four hours after segmental antigen lung challenge. J Allergy Clin Immunol 1993; 92: 607-615

66 Julius $P$, Lommatzsch M, Küpper $M$ et al. Safety of segmental allergen challenge in human allergic asthma. J Allergy Clin Immunol 2008; 121: $712-717$

67 Lommatzsch M, Virchow JC Jr. Die allergische Entzündung der oberen und unteren Atemwege. Allergologie 2002; 25: 96-107

68 Laitinen LA, Laitinen A, Haahtela T. A comparative study of the effects of an inhaled corticosteroid, budesonide, and a beta 2-agonist, terbutaline, on airway inflammation in newly diagnosed asthma: a randomized, double-blind, parallel-group controlled trial. J Allergy Clin Immunol 1992; 90: $32-42$

69 Khor YH, Feltis BN, Reid DW et al. Airway cell and cytokine changes in early asthma deterioration after inhaled corticosteroid reduction. Clin Exp Allergy 2007; 37: 1189-1198

70 Boman G, Ludviksdottir D, Janson C et al. Exhaled nitric oxide and its relationship to airway responsiveness and atopy in asthma. Respir Med 2008; 93: $552-556$

71 Leuppi JD, Downs SH, Downie SR et al. Exhaled nitric oxide levels in atopic children: relation to specific allergic sensitisation, AHR, and respiratory symptoms. Thorax 2002; 57: 518-523

72 Henriksen AH, Lingaas-Holmen T, Sue-Chu M et al. Combined use of exhaled nitric oxide and airway hyperresponsiveness in characteri- 
zing asthma in a large population survey. Eur Respir J 2000; 15: 849 855

73 Smith $A D$, Cowan JO, Brasset KP et al. Use of exhaled nitric oxide measurements to guide treatment in chronic asthma. N Engl J Med 2005; 352: $2163-2173$

74 Shaw DE, Berry MA, Thomas $M$ et al. The use of exhaled nitric oxide to guide asthma management. Am J Respir Crit Care Med 2007; 176: $231-237$

75 Szefler S, Mitchell H, Sorkness CA et al. Management of asthma based on exhaled nitric oxide in addition to guideline-based treatment for inner-city adolescents and young adults: a randomised controlled trial. Lancet 2008; 372: $1065-1072$

76 Baur X, Barbinova L. Messung von exhaliertem Stickstoffmonoxid. Klinischer Einsatz bei Atemwegserkrankungen. Dt Ärztebl 2009; 104: A790 - A796

77 Dressel H, de la Motte D, Reichert J et al. Exhaled nitric oxide: independent effects of atopy, smoking, respiratory tract infection, gender and height. Respir Med 2008; 102: 962 - 969

78 Olin A-C, Rosengren A, Thelle DS et al. Height, age, and atopy are associated with fraction of exhaled nitric oxide in a large adult general population sample. Chest 2006; 130: 1319-1325

79 Olin A-C, Bake B, Torén K. Fraction of exhaled nitric oxide at $50 \mathrm{ml} / \mathrm{s}$. Chest 2007; 131: 1852-1856

80 Kaiser KB. Risk factors in allergy/asthma. Allergy Asthma Proc 2004; 25: 7 - 10

81 Wenzel SE. Mechnisms of severe asthma. Clin Exp Allergy 2003; 33: $1622-1628$

82 Hashimoto T, Akiyama K, Kawaguchi H et al. Correlation of allergeninduced IL-5 and IL-13 production by peripheral blood T cells of asthma patients. Int Arch Allergy Appl Immunol 2004; 134: 7-11

83 Zhu Y, Chen L, Huang Z et al. Cutting edge: IL-5 primes the Th2 cytokine-producing capacity in eosinophils through a STAT5-dependent mechanism. J Immunol 2004; 173: 2918-2922

84 Kardos P, Brutschke M, Buhl $R$ et al. Kombination von Asthma und COPD: Häuftiger als erwartet? Pneumologie 2006; 60: 366 - 372

85 Mandell LA, Wunderink RG, Anzueto A et al. Infectious Diseases Society of America/American Thoracic Society consensus guidelines on the management of community-acquired pneumonia in adults. Clin Infect Dis 2007; 44: $27-72$

86 Ruiz M, Ewig S, Marcos MA et al. Etiology of community-acquired pneumonia: impact of age, comorbidity, and severity. Am J Respir Crit Care Med 1999; 160: 397-405

87 Ruiz M, Ewig S, Torres A et al. Severe community-acquired pneumonia. Risk factors and follow-up epidemiology. Am J Respir Crit Care Med 1999; 160: 923 -929

88 Hoheisel GB, Winkler J, Gessner C et al. Klinik und Diagnose bronchopulmonaler Infektionen im Alter. Pneumologie 2008; 62: 297 - 304

89 Kothe H, Bauer T, Marre $R$ et al. Outcome of community-acquired pneumonia: influence of age, residence status and antimicrobial treatment. Eur Respir J 2008; 32: 139-146

90 Krüger S, Ewig S, Marre R et al. Procalcitonin-predicts patients at low risk of death from community-acquired pneumonia across all CRB-65 classes. Eur Respir J 2008; 31: 349-355

91 Frank JA, Polly E, Parsons E et al. Pathogenetic significance of biological markers of ventilator-associated lung injury in experimental and clinical studies. Chest 2006; 130: 1906 - 1914

92 Gibot S, Cravoisy A, Kolopp-Sarda MN et al. Time-course of STREM (soluble triggering receptor expressed on myeloid cells)-1, procalcitonin, and C-reactive protein plasma concentrations during sepsis. Crit Care Med 2005; 33: $792-796$

93 Christ-Crain M, Breidthardt T, Stolz D et al. Use of B-type natriuretic peptide in the risk stratification of community-acquired pneumonia. J Intern Med 2008; 264: 166-176

94 Fraunberger P, Walli AK. Biomarker bei Sepsis und Entzündung. J Lab Med 2008; 31: 294-309

95 Póvoa P. Serum markers in community-acquired pneumonia and ventilator-associated pneumonia. Curr Opin Infect Dis 2008; 21: 157 162

96 Schütz P, Christ-Crain M, Müller B. Procalcitonin and other biomarkers for the assessment of disease severity and guidance of treatment in bacterial infections. Adv Sepsis 2008; 6: 82-89

97 Müller B, Schütz P, Trampuz A. Circulating biomarkers as surrogates for bloodstream infections. Int J Antimicro Agents 2007; 30: 16-23
98 Briel M, Schütz P, Müller B, Christ-Crain M et al. Procalcitonin-guided antibiotic use vs a standard approcach for acute respiratory tract infections in primary care. Arch Intern Med 2008; 168: 2000-2007

99 Christ-Crain M, Jaccard-Stolz D, Bingisser R et al. Effect of a procalcitonin-guided treatment on antibiotic use and outcome in lower respiratory tract infections: cluster-randomised, single-blinded intervention trial. Lancet 2004; 363: 600-607

100 Müller B, Schütz P, Christ-Crain M. Procalcitonin. Schweiz Med Forum 2008; 8: $388-390$

101 Kofoed K, Andersen O, Kronborg G et al. Use of plasma C-reactive protein, procalcitonin, neutrohils, macrophage migration inhibitory factor, soluble urokinase-type plasminogen activator receptor, and soluble triggering receptor expressed on myeloid cells- 1 in combination to diagnose infections: a prospective study. Critical care 2007; 11 R38 (doi:10.1186/cc5723)

102 Pai M, Zwerling A, Menzies D. Systematic review: T-cell-based assays for the diagnosis of latent tuberculosis infection: an update. Ann Intern Med 2008; 149: 177-184

103 Wagner D, Hörster R, Lange B et al. Stellenwert der T-Zell-Interferongamma-Sekretionstests in der Tuberkulosediagnostik. Dtsch Med Wschr 2008; 133: $354-357$

104 Storla DG, Kristiansesn I, Oftung F et al. Use of interferon gamma-based assay to diagnose tuberculosis infection in health care workers after short term exposure. BMC Infect Dis 2009; 9: 60 (doi: 10.1186/ 1471-2334-9-60)

105 Mack U, Migliori GB, Sester M et al. LTBI: latent tuberculosis infection or lasting immune responses to $\mathrm{M}$. tuberculosis? A TBNET consensus statement. Eur Respir J 2009; 33: 956 - 973

106 Arend SM, Engelhard AC, Groot G et al. Tuberculin skin testing compared with T-cell responses to Mycobacterium tuberculosis-specific and nonspecific antigens for detection of latent infection in persons with recent tuberculosis contact. Clin Diagn Lab Immunol 2001; 8: 1089 1096

107 Vier H, Gillissen A. Tuberkulosediagnostik: So wird der Verdacht zur Gewissheit. PneumoNews 2008; 2: 39

108 Lange C, Schaberg T, Diel R et al. Aktueller Stand der Tuberkulosediagnostik. Dtsch Med Wschr 2006; 131: 341 - 347

109 Lalvani A. Diagnosing tuberculosis infection in the 21st century: new tools to tackle an old enemy. Chest 2007; 131: 1898 - 1906

110 Dosanjh DP, Hinks TS, Innes JA et al. Improved diagnostic evaluation of suspected tuberculosis. Ann Intern Med 2008; 148: 325 - 336

111 Saltini C, Amicosante M. Beryllium disease. Am J Med Sci 2001; 321: 89-98

112 Lynch JP III, Toews GB. Idiopathic pulmonary fibrosis. In: Fishman AP Elias JA, Fishman JA et al., Hrsg Fishman's pulmonary diseases and disorders. New York: McGraw Hill, 1998: 1069-1084

113 Perez T, Remy-Jardin M, Cortet B. Airways involvements in rheumatoid arthritis. Am J Respir Crit Care Med 1998; 157: 1658-1665

114 Misumi S, Lynch DA. Idiopathic pulmonary fibrosis/usual interstitialpneumonia. Imaging diagnosis, specturm of abnormalities, and temporal progression. Proc Am Thorac Soc 2006; 3: 307-314

115 Ryu JH, Myers JL, Capizzi SA et al. Desquamative interstitial pneumonia and respiratory bronchiolitis-associated interstitial lung disease. Chest 2005; 127: 178-184

116 Martinez FJ. Idiopathic interstitial pneumonias. Usual interstitital pneumonia versus nonspecific pneumonia. Proc Am Thorac Soc 2006; $3: 81$ - 95

117 American Thoracic Society, European Respiratory Society. American Thoracic Society/European Respiratory Society international multidisciplinary consensus classification of the idiopathic interstitial pneumonias. Am J Respir Crit Care Med 2002; 165: 277 - 304

118 Katzenstein AL, Myers JL. Idiopathic pulmonary fibrosis: clinical relevance of pathologic classification. Am J Respir Crit Care Med 1998; 157: 1301 - 1351

119 Lacasse Y, Selman M, Costabel U et al. Clincial diagnosis of hypersensitivity pneumonitis. Am J Respir Crit Care Med 2003; 168: 952 - 958

120 Ziegenhagen MW, Rothe M, Schlaak M et al. Bronchoalveolar and serological parameters reflecting the severity of sarcoidosis. Eur Respir J 2003; 21: $407-413$

121 Lammi L, Kinnula VL, Lähde S et al. Propeptide levels of type III and type I procollagen in the serum and bronchoalveolar lavage fluid of patients with pulmonary sarcoidosis. Eur Respir J 1997; 10: 2725 2730 
122 Li X, Molina-Molina M, Abdul-Hafez A et al. Angiotensin converting enzyme-2 is protective but downregulated in human and experimental lung fibrosis. Am J Physiol Lung Cell Mol Physiol 2008; 295: L178 L185

123 Suga M, Iyonaga K, Ichiyasu H et al. Clinical significance of MCP-1 levels in BALF and serum in patients with interstitital lung diseases. Eur Respir J 1999; 14: $376-382$

124 Agostini C, Gurrieri C. Chemokine/cytokine cocktail in idiopathic pulmonary fibrosis. Proc Am Thorac Soc 2006; 3: 357 - 363

125 Guo X, Lin H-M, Lin Z et al. Surfactant protein A and B genetic variants predispose to idiopathic pulmonary fibrosis. Eur Respir J 2001; 18: 482- 490

126 Pardo A, Selman M. Idiopathic pulmonary fibrosis: new insights in its pathogenesis. Int J Biochem Cell Biol 2002; 34: 1534-1538

127 Hyzy R, Huang S, Myers J et al. Acute exacerbation of idiopathic pulmonary fibrosis. Chest 2007; 132: $1652-1658$

128 Nagai S, Handa T, Ito Y et al. Bronchoalveolar lavage in idiopathic interstitital lung diseases. Semin Respir Crit Care Med 2007; 28: 496 503

129 Ryu YJ, Chung MP, Han J et al. Bronchoalveolar lavage in fibrotic idiopathic interstitital pneumonias. Respir Med 2007; 101: 655-660

130 Govender P, Baugh JA, Pennington SR et al. Role of proteomics in the investigation of pulmonary fibrosis. Expert Rev Proteomics 2007; 4: $379-388$

131 Kriegova E, Melle C, Kolek V et al. Protein profilces of bronchoalveolar lavage fluids from patients with pulmonary sarcoidosis. Am J Respir Crit Care Med 2006; 173: 1145-1154

132 Meyer G, Planquette B, Sanchez O. Long-term outcome of pulmonary embolism. Curr Opin Hematol 2008; 15: 499-503

133 DeMonaco NA, Dang Q Kapoor WN et al. Pulmonary embolism incidence is increasing with use of spiral computed tomography. Am J Med 2008; 121: 611-617

134 British Thoracic Society. British Thoracic Society guidelines for the management of suspected acute pulmonary embolism. Thorax 2003; 58: $470-484$

135 Kline JA, Hernandez-Nino J, Rose GA et al. Surrogate markers for adverse outcomes in normotensive patients with pulmonary embolism. Crit Care Med 2006; 34: 2773-2780

136 Aksay E, Yanturali S, Kiyan S. Can elevated tropinin I levels predict complicated clinical course and inhospital mortality in patients with acute pulmonary embolism? Am J Emerg Med 2007; 25: 138-143

137 Pruszczyk P, Kostrubiec M, Bochowicz A et al. N-terminal pro-brain natriuretic peptide in patients with acute pulmonary embolism. Eur Respir J 2003; 22: 649-653

138 Stolba $R$, Lenglinger $F$, Rezenka $E$ et al. Wertigkeit eines neuen, quantitativen D-Dimer-Test für die Ausschlußdiagnostik von Pulmonalembolien bei symptomatischen Patienten. J Lab Med 2000; 24: 153 -157

139 Michiels IJ, Gadisseur A, Planken Mv d et al. A critical appraisal of noninvasive diagnosis and exlusion of deep vein thrombosis and pulmonary embolism in outpatients with suspected deep vein thrombosis or pulmonary embolism: how many tests to we need? Int Angiol 2005; $24: 27-39$

140 Nordenholz KE, Mitchel AM, Kline JA. Direct comparison of the diagnostic accuracy of fifty protein biological markers of pulmonary embolism for use in the emergency department. Acad Emerg Med 2008; 15: $795-799$

141 Christopher Study Investigators. Effectiveness of managing suspected pulmonary embolism using an algorithm combining clinical probability, D-dimer testing, and computed tomography. JAMA 2006; 295 : 179
142 Mitchell AM, Nordenholz KE, Kline JA. Tandem measurment of D-dimer and myeloperoxidase or C-reactive protein to effectively screen for pulmonary embolism in the emergency department. Acad Emerg Med 2008; 15: $800-805$

143 Horvath I, Hunt JF, Barnes PJ. Exhaled breath condensate: methodological recommendations and unresolved questions. Eur Respir J 2005; 26: $523-548$

144 Chan HP, Lewis C, Thomas PS. Exhaled breath analysis: Novel approaches for early detection of lung cancer. Lung Cancer 2008; 63: $164-168$

145 Conrad DH, Goyette J, Thomas PS. Proteomics as a method for early detection of cancer: a review of proteomics, exhaled breath condensate, and lung cancer screening. J Gen Intern Med 2007; 23: 78 - 84

146 Gray RD, MacGregor G, Noble D et al. Sputum proteomics in inflammatory and suppurative respiratory diseases. Am J Respir Crit Care Med 2008; 178: 444-452

147 Merkel D, Rist W, Seither P et al. Proteomic studyof human bronchoalveolar lavage fluids from smokers with chronic obstructive pulmonary disease by combining surface-enhanced laser desorption/ionization-mass spectrometry profiling with mass spectrometric protein identification. Proteomics 2005; 5: 2972-2980

148 Martin P, Makepeace K, Hille SA et al. Microsatellite instability regulates transcription factor binding and gene expression. Proc Natl Acad Sci USA 2005; 102: $3800-3804$

149 Carpagnano GE, Foschino-Barbaro MP, Spanevello A et al. 3p microsatellite signature in exhaled breath condensate and tumor tissue of patients with lung cancer. Am J Respir Crit Care Med 2008; 177: 337 341

150 Zervou MI, Tzortzaki EG, Makris D et al. Differences in microsatellite DNA level between asthma and chronic obstructive pulmonary disease. Eur Respir J 2006; 28: 472 - 478

151 Makris D, Tzanakis N, Damianaki A et al. Microsatelite DNA instability and COPD exacerbations. Eur Respir J 2008; 32: 612 - 618

152 Mazzone PJ, Hammel J, Dweik D et al. Diagnosis of lung cancer by the analysis of exhaled breath with a colorimetic sensor array. Thorax 2007; 62: $565-568$

153 Dragoneri S, Schot R, Mertens BJ et al. An electronic nose in the discrimination of patients with asthma and controls. J Allergy Clin Immunol 2007: $120: 856-862$

154 Belda-Iniesta C, de Castro Carpeno J, Carrasco JA et al. New screeing method of lung cancer by detecting volatile organic compounds in breath. Clin Transl Oncol 2007; 9: 364 - 368

155 Dragonieri S, Annema JT, Schot R et al. An electronic nose in the discrimination of patients wiht non-small cell lung cancer and COPD. Lung Cancer 2008; 64: 166-170

156 Machado RF, Laskowski D, Deffenderfer O et al. Detection of lung cancer by sensory array analyses of exhaled breath. Am J Respir Crit Care Med 2005; 17: 1286-1291

157 Moorhead KT, Lee D, Chase JG, Moot AR et al. Classifying algorithmus for SIFT-MS technology and medical diagnosis. Comput Methods Programs Biomed 2008; 89: 226-238

158 Gaspar EM, Lucena AF, Duro da Costa J et al. Organic metabolites in exhaled human breath: a multivariate approach for identification of biomarkers in lung disorders. J Chromatogr A 2008; 1216: 2749 2756

159 Buszewski B, Ulanowska A, Ligor $T$ et al. Analysis of exhaled breath from smokers, passive smokers and non-smokers by solid-phase microextraction gas chromatographie/mass spectrometry. Biomed Chromatogr 2008; 23: $551-556$ 